\title{
Non-Hodgkin's lymphoma in pregnancy: prenatal clinical assessment
}

\begin{abstract}
Summary
This case report aims to present the clinical aspects suggestive of non-Hodgkin's lymphoma in a second trimester pregnant woman. A quality prenatal visit can favor the early diagnosis of cancer in pregnancy and enable safe treatment for mother and fetus.
\end{abstract}

Keywords: non-hodgkin's lymphoma, pregnancy, prenatal
Volume 3 Issue 4 - 2017

\author{
Flaviana Vieira, Guimarães JV, Siqueira KM \\ Doctor of Nursing, Professor of the Nursing, Federal University \\ of Goiás, Brazil
}
Correspondence: Flaviana Vieira, Doctor of Nursing, Professor of the Nursing, Federal University of Goiás, Brazil, Email flavianamori@gmail.com

Received: June 26, 2017 | Published: July 27, 2017

\section{Introduction}

In pregnancy there are physiological changes, however, some changes should not be considered normal. Lack of appetite and nausea in the first trimester, for example, can lead to weight loss. ${ }^{1}$ However, a perception and assessment of normality of the clinical signs and symptoms of gestation may mask some disease, which can sometimes be severe and enable a high-risk pregnancy.

Overall, the incidence of cancer has increased, although not often, cancer can occur in pregnancy. ${ }^{2-4}$ Thus, health professionals need to be prepared to properly identify, treat and follow these pregnancies. Lymphomas are morphologically subdivided into Hodgkin's lymphoma and non-Hodgkin's lymphoma, forming a group of malignant neoplastic diseases that originate from cells of the immune system, accounting for $5 \%$ of cancer deaths..$^{5-7}$

Knowledge of the clinical aspects of lymphoma in a second trimester pregnancy may contribute to the attention to the clinical physical examination in the prenatal consultations and consequent directing of the fast and adequate clinical management. This case report aims to present the clinical aspects of non-Hodgkin's lymphoma in the second trimester of gestation.

\section{Case presentation}

36 year old pregnant woman, married, full college, first gestation, planned. She used intrauterine devices, taken three months before pregnancy. Pre-conception: results of normal/non-reactive tests in the investigation with complete blood count, glycemia, urine type I, T3, T4 and TSH, anti-HIV, HTLV1 and 2, VDRL, hepatitis B and C, Chagas, serology for cytomegalovirus, Serology for toxoplasmosis, serology for rubella, cytopathology for the screening of cervical cancer, mammography and breast ultrasonography.

Weight $59 \mathrm{~kg}$, appropriate BMI.

\section{I ${ }^{\text {st }}$ Prenatal visit}

Pregnant referred to fatigue. Pre-conception laboratory tests were repeated and remained normal/non-reactive. Obstetric ultrasound with single gestation, with 9 weeks of gestation. Weight 59 kilograms, with appropriate BMI.

\section{$2^{\text {nd }}$ Prenatal visit}

Pregnant (13 weeks) reported having a good time, but, she maintained fatigue and lack of appetite. Weight $59 \mathrm{~kg}$. BMI appropriate. It was the thirteenth week of gestation.

\section{$3^{\text {rd }}$ Prenatal visit}

Pregnant woman (17 weeks) reported lack of appetite, fatigue, frequent dry cough, body pruritus and small protuberance in the sternum. Weight $59 \mathrm{~kg}$. Chest X-ray was avoided due to gestation.

\section{$4^{\text {th }}$ Prenatal visit}

Pregnant (22 weeks) reported worsening of the symptoms of the previous month, with night sweats, difficulty swallowing, increased external bulge, engorgement of jugular veins and presence of enlarged lymph nodes in region above clavicle. There was no fever. Weight $59 \mathrm{~kg}$.

\section{$23^{\text {rd }}$ Week of gestation}

MRI of the thorax suggested cancer in the anterior mediastinum, with massive expansive/infiltrative formation in the mediastinum, measuring around $9.4 \mathrm{cmx} 4.5 \mathrm{~cm}$, limited evaluation in the study due to the non-use of contrast.

\section{$26^{\text {th }}$ Week of gestation}

Confirmation of the diagnosis of diffuse non-Hodgkin's lymphoma of large B cells. Staging II with symptoms B. Onset of chemotherapy.

\section{Proposed treatment}

Six cycles of chemotherapy and follow-up of pregnancy. Gestation continued up to 37 weeks and 3 days, healthy baby and mother complete treatment response. Postpartum radiation therapy.

\section{Discussion}

The diffuse non-Hodgkin's lymphoma of large B cells, considered to be of high degree, presents high cell proliferation index, large cells, localized lymph node enlargement, being characterized as aggressive, leading to survival from weeks to months if not treated. ${ }^{7}$ Currently, the incidence of non-Hodgkin's lymphoma tends to increase. Although 
rare, it represents the fourth leading cause of cancer in pregnancy, from 1 in 6,000 pregnancies. ${ }^{8,9}$ The increased incidence requires professionals to pay more attention in prenatal clinical modifications, ${ }^{10}$ differentiate what is common in pregnancy and what is clinical change that requires priority in care and treatment. Although the diagnosis was not so early, it was still the well-conducted physical examination that guided the appropriate imaging examination. Thus, having the diagnosis in time to treat the mother without harm to the baby.

In Brazil, both in the Unified Health System and a supplementary health or private service, pregnant women are followed monthly up to 28 weeks gestation, fortnightly up to 36 weeks, and weekly after 36 weeks. Laboratory tests are routinely performed: blood count; Blood group and Rh; Glycemia; Anti-HIV; VDRL; Urine routine; Serology for toxoplasmosis and rubella, in some regions of the country are also made: serology for cytomegalovirus; Hepatitis $\mathrm{B}$ and $\mathrm{C}$; Chagas disease; HTLV 1 and 2; T3, T4 and TSH. In prenatal consultations, in addition to routine exams, assessments of: personal and family history, previous and current obstetric data, and general and obstetric physical examination are recommended at all visits. ${ }^{1,4}$ The fourth prenatal visit was the milestone for the suspected cancer. The diagnosis was possible due to the integral evaluation provided during the prenatal consultations and the continued care and attention to the evolution of the pregnant woman's clinical picture. In general and initially, the evaluation of the patient with non-Hodgkin's lymphoma includes anamnesis and physical examination. About $70 \%$ of the patient's present lymphadenopathy and B symptoms (fever, night sweats and weight loss) are observed in about $40 \%$, indicating aggressive disease. Approximately $20 \%$ of the patients present meditational mass and 3\% to $8 \%$ may have upper vena cava syndrome. ${ }^{7}$ The pregnant woman was included in the clinical aspects that most patients with non-Hodgkin's lymphoma present. Of the B symptoms had no fever, on the other hand, presented sweating and maintained the same pre-gestational weight, the expected weight gain would be for the gestational age. Also present meditational mass and superior vena cava syndrome.

Cancer in pregnancy becomes extremely complex for the pregnant and difficult to manage for health professionals. ${ }^{11} \mathrm{~A}$ woman, in addition to dealing with the inherent modifications of pregnancy, needs to confront the diagnosis and treatment of cancer plus the uncertainties of the prognosis for her and the baby. For health professionals still insecurity in handling rare cases like this. Case reports are pertinent to target future studies with larger prospective follow-up, in addition to supporting practitioners for the suspicion and management of nonHodgkin's lymphoma during pregnancy. ${ }^{11,12}$

\section{Conclusion}

The prenatal consultation with integral evaluation of the pregnant woman, in her obstetrical and clinical aspects, allowed the adequate guidance of the diagnosis of Hodgkin's lymphoma in the second trimester of pregnancy.

\section{Acknowledgements}

The pregnant woman who faced cancer during pregnancy.

\section{Conflict of interest}

The author declares no conflicts of interest.

\section{References}

1. Ministério da saúde. Atenção ao pré-natal de baixo risco. Brasil: Ministério da saúde; 2015. 318 p

2. Coordenação de prevenção e vigilância, Instituto Nacional de Câncer José Alencar Gomes da Silva Estimativa 2016: incidência de câncer no Brasil. Brasil: Rio de Janeiro; 2015. 122 p.

3. Pinnix CC, Andraos TY, Milgrom S, et al. The management of lymphoma in the setting of pregnancy. Curr Hematol Malig Rep. 2017;12(3):251256

4. Ministério da Saúde. Gestação de alto risco. Brasil: Ministério da Saúde, Brasília; 2010

5. World health organization. WHO Classification of tumours of haematopoietic and lymphoid tissue. Geneve, Switzerland: World health organization; 2014

6. Ministério da saúde. Clinical practice guidelines in oncology. Brasil: Ministério da Saúde; 2014. 356 p.

7. Araújo LHL, Victorino APS, Melo AC, et. al. Linfoma não-Hodgkin de alto grau-Revisão da literatura. Revista brasileira de cancerologia. 2008;54(2):175-183.

8. Monleón J, Goberna L, Monleón FJ. Cáncer y gestación. Clin Invest Ginecol Obst. 2006;33(3):80-92.

9. Tartas NE, Foncuberta MC, Sánchez Avalos JC. Tratamiento de las neoplasias hematológicas en el embarazo. Medicina. 2007;67(6):729736.

10. Diumenjo MC, Abriata G, Forman D, et al. The burden of nonhodgkin lymphoma in central and South America. Cancer Epidemiol. 2016;44(1):S168-177.

11. Dekrem J, Van Calsteren K, Amant F. Effects of fetal exposure to maternal chemotherapy. Paediatr Drugs. 2013;15(5):329-334.

12. Pinnix CC, Osborne EM, Chihara D, et. al. Maternal and fetal outcomes after therapy for hodgkin or non-hodgkin lymphoma diagnosed during pregnancy. JAMA Oncol. 2016;2(8):1065-1069. 